\title{
Health Demand and Outcomes in Pakistan
}

\section{Imran Ashraf Toor and Muhammad Sabihuddin Butt}

\begin{abstract}
For the provision of better social services, the health sector has been an important part of national strategy for reducing poverty and income disparities among different income groups in Pakistan. The distribution of access to and use of health among households has been a long-standing concern among policy makers. In this study, government health expenditure is treated as a fixed factor that influences housebold bealth behaviour, conditional on such factors as bousehold income, education, and family size. The results of the study suggest that government health expenditure is associated with higher use of both preventive and curative health services by children. The results also indicate that increased government expenditure is actually associated with lower use of health services by the children of the poor, although this negative association is generally weak. However, if increased government spending improves health care opportunities for the nonpoor more than for the poor, the total effect of government spending on the health outcomes of the poor could be less even though they have a higher marginal product of health care inputs.
\end{abstract}

\section{Introduction}

Investments in human capital are often highlighted as major contributors to the increased productivity of the country. It is now an opportune time to evaluate the contribution. This service has contributed to the goal of promoting growth and equity for two reasons. First, the guiding policy framework of the past two decades, offering a natural point for reevaluation. Second, the Government of Pakistan is currently reevaluating the relative roles of the government and the private sector in providing a wide range of infrastructure and social services. The distribution of access to and use of health among households has been a long-standing concern among

\footnotetext{
* The authors are Economist at Social Policy and Development Centre (SPDC), Karachi and Senior Research Economist at Applied Economics Research Centre, University of Karachi respectively. The usual caveat applies.

Author's Note: This article is an extension of the research done by Imran Ashraf Toor as an M Phil. student at Applied Economics Research Centre, University of Karachi. The authors would like to thank Dr. Nuzhat Ahmed for her valuable and helpful comments on an earlier draft of this article.
} 
economists. Relatively few studies have looked at the incidence of public expenditure on social services in developing countries. Important exceptions are the studies by Meerman (1979) for Malaysia and Selowsky (1979) for Colombia, which adopted the benefit-incidence methodology to calculate the benefits of social sector spending. In the benefit-incidence approach, estimated government unit subsidies for specific social services (for example health facilities) are attributed to households depending on their rates of use of these facilities.

Behrman and Deolalikar (1987) used panel data on rural South Indian households utilising a much wider and probably more reliable set of health status indicators. They estimate health and nutrient consumption status relations which allow for differing price and income responses by different household members (namely, adult males, adult females, male children, and female children) and which control for individual-specific fixed effects. ${ }^{1}$ Behrman and Wolfe (1987) find that without the deviation control, mother's schooling apparently has widespread positive health and nutrition effects. But once there is a control for unobserved family-origin endowments, the impact of maternal schooling on female health, child health and infant mortality is not significant. Their results thus raise doubts about standard estimates without control for unobserved mother's childhood-family background characteristics that claim to find strong positive health effects of women's schooling. However, they find neither a significant income effect nor significant differences in price or income responses across household members. ${ }^{2}$

Folbre, (1984a 1984b), developed reduced-form demand relations for health inputs and outcomes as dependent on prices, income, and various individual and household characteristic. ${ }^{3}$ Such relations are consistent with constrained maximisation of a unified preference function or with the bargaining framework. In either case, preferences are defined over the health status of individuals, and the constraints typically include a budget or income constraint and biological health production function for each individual. The state of health technology (embodied in, say, the education of the health care provider at home - typically, the mother), and on various environmental influences. ${ }^{4}$ Unlike Akin et al., (1987), find significant effects

${ }^{1}$ Behrman and Deolalikar (1987) estimated joint reduced-form equation.

2 Behrman and Wolfe (1987) (1987) estimated interfamilial deviation estimates for health and nutrition demand relations for the Nicaraguan sample.

3 Folbre (1984a, 1984b, 1986), Manser and Brown (1980), and McElroy and Horney (1981).

${ }^{4}$ Such as the availability of clean drinking water; See Behrman and Deolalikar (1987) for a generic household model of health determination in a developing country context. 
of a number of dimensions of prices - i.e. distance and quality measures. They do not explore, however, whether there are price effects on health status as opposed to the demand for health inputs.

The reduced-form regression strategy avoids many of the weaknesses of the benefit-incidence approach discussed earlier. First, the reduced-form approach let us work with direct measures of health status, such as incidence of morbidity, which arguably is a better indicator of consumer welfare and benefits than the use of health services. Second, since per capita government health expenditure reflects both the quantity as well as the quality of health services, the reduced-form approach permits variations in service quality to have an impact on health services use and on health outcomes. Third, the reduced-form approach allows for a private sector response to public health expenditure. Since the provision of private health services is not included as an explanatory variable in the individual behavioural equations, the estimated government expenditure effects include the indirect effect that social spending has on health outcomes and service use through stimulating the supply of private health services in an area. Finally, the approach adopted here allows us to control for household socioeconomic variables that are important determinants of health use and health status.

The intrahousehold allocation process results in a system of reducedform individual demand equations for health status, as well as derived demand equations for medical care and other health-related inputs. These reduced-form equations have as their arguments all prices (including the prices of food and medical care), household income, personal characteristics of household members, and relevant family- and community-specific variables. Within this very general framework, the public provision of medical care and other health goods (for example, clean drinking water and sanitation) as reflected in government health expenditure, can have important reduced-form effects on the health outcomes of individuals and on their demand for medical care. High per capita government health expenditure in a region may be associated with greater availability of health facilities and health services per capita.

Of course, one major reason for being concerned with the determinants of health is to provide a better basis for policy formation. What are the implications of the growing collection of empirical work on health for policy? Can the apparent greater price and income responsiveness of poorer members of society be utilised in more effective policies? What would be the distributional and health impact of increasing user charges or 
of new insurance schemes on different types of health inputs in a specific context?

With respect to the determination of health expenditures, major questions remain unsolved. What are the nature of the biological processes involved, the extent of substitutabilities and complementarities in the health production process, the nature of lags, and the role of nutrition? How important is women's education in determining health? Is its often significant role in standard estimates reflective of increased productivity in using given health-related inputs, or is it primarily proxying for unobserved individual and household endowments as suggested by the one available adult-sibling deviation study? Are education and public health measures substituted broadly, as Rosenzweig and Schultz suggest for their Colombian study?

The objective of the study is to evaluate the distributional benefit of government health expenditure in Pakistan using the reduced-form demand approach. Government health expenditure is treated as a fixed factor that influences household health behaviour, conditional on such factors as household income, education, and family size. The following questions are addressed. Is per capita government health expenditure associated with measures of use as well as with direct measures of health outcomes and status, after controlling for the socioeconomic factors that normally influence use and outcomes? Does the impact of government health expenditure on health services use and health outcomes differ significantly across economic groups?

\section{Theoretical Underpinning}

The study focuses on the reduced-form demand relations for health inputs and outcomes as dependent on prices, income, and various individual and household characteristics. Such relations are consistent with constrained maximisation of a unified preference function or with the bargaining framework emphasised by Folbre (1984a, 1984b, 1986), Menser and Brown (1980), and McElroy and Horney $(1981)^{6}$. In either case, preferences are defined over the health status of individuals, and the constraints typically include a budget or income constraint and biological health production

\footnotetext{
5 Rosenzweig and Schultz (1982a)

6 Available data generally do not permit testing a bargaining model with a fixed structure against the maximisation of common preferences. Rosenzweig and Schultz (1982a, 1982b) and McElroy and Horney (1981) among others, have argued that differential effects on human capital outcomes of unearned income accruing to husbands and wives provide support for the bargaining model.
} 
functions for each individual that characterise the 'production' of health from food, nutrition, and health care inputs, conditional on the health endowments of that individual, on the state of health technology (embodied in, say, the education of the health care provider at home - typically, the mother), and on various environmental influences (such as the availability of clean drinking water; see Behrman and Deolalikar (1987) for a generic household model of health determination in a developing-country context). The intrahousehold allocation process results in a system of reduced-form individual demand equations for health status, as well as derived demand equations for medical care and other health-related inputs. These reducedform equations have as their arguments all prices (including the prices of food and medical care), household income, personal characteristics of household members, and relevant family- and community-specific variables.

Government health expenditure affects health services use and health status identically across all individuals. This may be an overly restrictive assumption for a number of reasons. First, access to government health facilities may be unequal across economic groups. For example, urban dwellers may have disproportionately greater access to better-quality health care than rural households. To the extent that urban households are typically more affluent than rural households, the urban bias in government health expenditure could translate into larger health benefits for richer relative to poorer households. Because more than 65 percent of Pakistan lives in rural areas, an overwhelming section of medical personnel and health facilities are located only in cities. For example, 85 per cent of all practicing doctors work in the cities, which comes to a doctor-population ratio of 1:1801. The rural doctor-population ratio happens to be a pathetic 1:25829. Similarly, only 23 per cent of the hospitals in the country are located in rural areas and only 8,574 hospital beds ( 18 per cent of total) are available to a population of 80 million (Zaidi 2000). Second, there could be behavioural differences among individuals belonging to different income groups that might lead them to respond differently to identical levels of availability, quality, and price of health services. For instance, there is growing evidence to suggest that the price elasticity of demand for medical care is larger for the poor than for the nonpoor (Gertler and van der Gaag 1990). If this is indeed the case, an equivalent reduction in the price of medical care (induced, say, by an improved supply of public and private health services) would increase the poor's use of health services more than the nonpoor's. Third, identical use of health services (of the same quality) could be associated with different health outcomes due to biological differences across individuals. For instance, a diminishing marginal product of health care and other health inputs would imply that innately healthier individuals would benefit proportionately less from the same amount and 
quality of health care than would less healthy individuals. If health outcomes and incomes were positively associated with each other, one would then observe larger health gains for the poor from identical provision of health services.

To illustrate these effects, assume that individual health outcomes (H) are "produced" with only two inputs, government health services $(\mathrm{M})$ and private health services $(P)$ :

$$
\mathrm{H}=\mathrm{H}(\mathrm{M}, \mathrm{P}) ; \mathrm{H}^{\prime}>0 \text { and } \mathrm{H}^{\prime}<0
$$

The impact of aggregate government health spending $(G)$ on the health outcomes of the $i$ th economic group is then given by:

$$
\mathrm{MH}_{\mathrm{i}} / \mathrm{MG}=\left[\left(\mathrm{MH}_{\mathrm{i}} / \mathrm{MM}_{\mathrm{i}}\right)\left(\mathrm{MM}_{\mathrm{i}} / \mathrm{MG}\right)\right]
$$

A priori, both $M H_{i} / M M_{i}$ (the marginal product of public medical care) are likely to be greater for low-income than for high-income groups, since the former typically consume lower quantities of medical care. However, the total impact of aggregate government spending on the health outcomes of the ith economic group also depends on how aggregate government spending influences the supply of public medical services. If an additional rupee of government health spending increases access to medical care for the nonpoor much more than for the poor, $M H_{i} / \mathrm{M} G$ could be greater for the nonpoor than for the poor.

\section{Empirical Model}

This study focuses on the demand for health status and the derived demand for health-related inputs for children under five years of age. Since differences across economic groups are an important concern of the chapter, the parameters of the demand relations are allowed to depend (log-linearly) on household expenditure per capita. The equations [derived by Deolalikar (1995)] to be estimated are:

$$
\begin{aligned}
& H_{i j}=a_{1}(Y)+a_{2}(Y) X_{i j}+a_{3}(Y) Z_{i j}+a_{4}(Y) G_{j}+\mu i j \\
& a_{k}=a_{k 1}+a_{k 2} Y, k=1, \ldots 4,
\end{aligned}
$$

where

$\mathrm{i}=$ indexes the individual child; 


$$
\begin{aligned}
& j=\text { indexes the province of residence; } \\
& H=\text { vector of health care inputs and health outcomes; } \\
& Y=10 g \text { household monthly expenditure per capita; } \\
& X=\text { vector of individual characteristics (age and sex); } \\
& Z=\text { vector of household characteristics, including } Y \text {; } \\
& G=10 \text { government health expenditure per capita; and } \\
& \mu=\text { stochastic disturbance term. }
\end{aligned}
$$

It is important to note that since the relations in equation 3 are of the reduced form, all dependent variables - whether health inputs or health outcomes - have the same set of explanatory variables. Also, since an individual's health status is a cumulative outcome of health care and other (nutritional) inputs over a number of years, the analysis implicitly assumes that the explanatory variables reflect medium- or long-run living standards of households and communities and not just living standards in the year of the survey. This, in turn implies that the explanatory variables, including provincial government health expenditures per capita, have been stable over time. The vector of health care inputs $(\mathrm{H})$ includes both curative care (whether any treatment and whether treatment from a modern health care provider - physician or paramedic - was sought for an illness during the time of interview) and preventive care (whether the child has been immunised against DPT, measles or polio). Since all these variables are dichotomous in nature, the corresponding equations are estimated by the maximum likelihood logit method.

The individual child characteristics $(\mathrm{X})$ that are included in the health demand relations are sex, age (in months), and age squared. The vector of household characteristics $(\mathrm{Z})$ includes household size, urban/rural status of residence, age of the household head, schooling of the child's mother and of the household head, and the natural log of household per capita monthly expenditure. The coefficient $\mathrm{a}_{4}(\mathrm{Y})$ in relation 3 represents the marginal effect of $\log$ government health expenditure on health services use and on health outcomes, controlling for observed household and individual characteristics such as age, education, and household per capita expenditure. In practice, however, when the government increases social spending, there is typically no control for other effects. For policy purposes, it may he useful to know how increased social spending affects poor 
households, whatever their characteristics. For this reason, we also estimate an ultimate reduced-form version of relation 3 in which the only regressor is $\log$ per capita government health expenditure. The coefficient of this model indicates the impact of government health expenditure without controlling for any household or individual characteristics.

\section{- Variables Specification}

Any Immunisation: Immunisation is a method of making a child immune to disease by injecting certain substances into the body, which stimulate the production of disease-fighting antibodies. Commonly, immunisation for children comprises a series of vaccinations e.g., BCG (antiTB); DPT (anti-diphtheria/whooping cough/tetanus), anti-polio (drops), given orally not by injection; anti-measles, administered at specific intervals. Children reported as having received at least one immunisation during the survey period.

Reported Episodes: Diarrhea: It is when the stool is like a liquid and the number of stools is more than the usual (generally 3 or more). Dysentery or any other disease is not included in this section, although loose, frequent stools may be reported.. If stools are bloody and contain mucous, assume that the child has dysentery rather than diarrhea. In the light of this definition, record the response. The reference period for the occurrence of diarrhea is last 30 days from the date of the interview.

Duration of Reported Episodes: Number of days are reported of those children who suffered from diarrhea of age 5 years and under. The number of days the child has had diarrhea during the last 30 days. If the child had more than one episode of diarrhea during the last 30 days, sum up the total number of days of all episodes.

Any Treatment: To consult means being examined by a doctor, nurse, pharmacist, LHW, faith health/other health practitioner (hakeem, homeopath, etc.). To diagnose the illness (diarrhea) of the person who is suffering and to prescribe treatment.

Modern Treatment: The variable comprises children getting medical treatment for diarrheal disease from government dispensary/ government hospital, basic health unit, rural health centre, $\mathrm{MCH}$ centre, private doctor, and private hospital.

Child Age: This variable reports the age of child. The maximum age of the child which is used in this study is 5 years. 
Whether Male: To capture the gender effect, we use male as a dummy variable in this study. If the child is a male then we use one otherwise zero.

Age of Household Head: This variable consists of the age of the household head. It is included to capture the cohort effect of the family head.

Schooling years of household head: To capture the effect of educational level of the household head on the child's health status.

Schooling years of mother: The completed years of education of mother is included in the set of explanatory variables. According to the previous studies, children whose mothers have higher education levels are more likely to avail of health facilities. Thomas (1990) demonstrates that education primarily affects access to information. In this study, an attempt is made to understand better the role of maternal education by introducing the interactions between education and community services to capture the substitutability or complementarity between provision of public services and mother's education.

Whether urban residence: The sample size of the PIHS 1996-97 was fixed at a level high enough to allow estimates to be obtained for regions (urban/rura1). To capture the effect of recurrent government health expenditure on their people. The data of this variable is taken from Provincial Annual Budget Reports.

Per capita recurrent government health expenditure in province of residence: Every year the government allocates health expenditure to provide health facilities at their residence. Four provinces have different allocations for this purpose. This variable is used to capture the effect of recurrent government health expenditure on their people. The data of this variable is taken from Provincial Annual Budget Reports.

Household per capita monthly expenditure: In order to assess the extent to which poorer and richer households have benefited from improved service access and welfare, data is needed on household consumption or income. In this study, per capita monthly expenditures have been used to divide households.

Household size: Household members are all such persons or group of persons in a household who normally live and eat together and consider the living quarter/space occupied by them as their usual place of residence. Such 
persons may be related or unrelated to each other. All such persons who normally live and eat in the household and are present at the time of enumeration and those who are temporarily absent for reasons such as, visiting, traveling in connection with business, attending schools/colleges/ other educational institutions etc., are treated as household members.

\section{Data Source}

The data for this article was taken from Pakistan Integrated Household Survey 1996-97 (PIHS). In this survey, a two-stage random sampling strategy was adopted for data collection. At the first sampling stage, a number for clusters or Primary Sampling Units (PSUs) were selected from different parts of the country. Enumerators then compiled lists of all households residing in the selected PSUs. At the second sampling stage, these lists were subsequently used to select a fixed number of households from each PSU for interviews using a systematic sampling procedure with a random start. This two-stage sampling strategy was used in order to reduce survey costs, and to improve the efficiency of the sample. The number of PSUs to be drawn from each strata in the first stage was fixed so as to ensure that there were enough observations to allow representative statistics to be derived for each main strata of interest.

In each of the selected PSUs, a fixed number of households were selected at random (12 in each urban PSU, 16 in each rural PSU), and a detailed household questionnaire was administered to each of them. In addition, in each rural PSU, a community questionnaire was also completed which gathered information on the quality of infrastructure, the provision of services, and consumer prices prevailing in the community. The sample size for the 1996-97 PIHS was 12,381 households and 84,762 individuals, approximately 60 percent of which was rural. These covered all four provinces Punjab, Sindh, NWFP and Balochistan.

At the individual and household level, the PIHS collects information on a wide range of topics using an integrated questionnaire. The household questionnaire comprises a number of different modules, each of which looks at a particular aspect of household behaviour or welfare. Data collected under Round II included educational attainment and health status of all household members. In addition, information was also sought on the maternity history and family planning practices of all eligible household members. Finally, data was also collected on the household's consumption of goods and services in the last fortnight/month/year, as well as on housing conditions and access to basic services and amenities such as school, water and health center. 


\section{Differences in health inputs and health outcomes across income groups}

Table 1 and 2 report the mean levels of health care inputs and health outcomes for the entire sample as well as for three expenditure classes (low, middle, and high) separately. The low-expenditure class includes children whose household per capita expenditure falls below Rs. 500. This cut off point corresponds closely to commonly used Pakistan Integrated Household Survey 1996-97. The middle-expenditure group includes children having household per capita expenditure between Rs. 500 to Rs. 1000. All other observations fall in the high-expenditure class. Table1 and Table-2 show the descriptive statistics of the different income groups.

Table1: Descriptive Statistics for Sample of Children Under Five Year

\begin{tabular}{lrrrr}
\hline \multicolumn{1}{c}{ Variables } & All Households & \multicolumn{2}{c}{$\begin{array}{c}\text { Low Expenditure } \\
\text { Households }\end{array}$} \\
\hline Any Treatment (0,1) & Mean & $\begin{array}{c}\text { Standard } \\
\text { Dev. }\end{array}$ & Mean & $\begin{array}{c}\text { Standard } \\
\text { Dev. }\end{array}$ \\
\hline Modern Treatment (0,1) & 0.96 & 0.21 & 0.94 & 0.24 \\
Any Immunisation (0,1) & 0.74 & 0.44 & 0.66 & 0.47 \\
Reported Episodes (\#) & 0.79 & 0.41 & 0.77 & 0.42 \\
Duration of Reported Episodes (\#) & 0.15 & 0.36 & 0.15 & 0.36 \\
Child Age (Months) & 6.86 & 5.25 & 7.93 & 5.66 \\
Child Age Square (Months) & 35.07 & 19.23 & 35.45 & 19.49 \\
Whether Male (0,1) & 1599.20 & 1346.39 & 1636.45 & 1366.36 \\
Age of Household Head (Year) & 0.500 & 0.50 & 0.51 & 0.50 \\
Schooling Years of Household Head (Year) & 38.06 & 8.83 & 39.156 & 9.14 \\
Schooling Years of Mother (Year) & 4.45 & 5.06 & 2.72 & 3.97 \\
Whether Urban Residence (0,1) & 1.54 & 3.45 & 0.69 & 2.22 \\
Per capita Recurrent Government Health & 0.36 & 0.48 & 0.29 & 0.45 \\
Expenditure in Province of Residence (Rs.) & 102.92 & 22.37 & 95.94 & 20.34706 \\
Household Per Capita Monthly Expenditure (Rs.) & 695.51 & 472.29 & 405.40 & 9 \\
Household Size (\#) & 8.19 & 3.36 & 8.95 & 63.89 \\
Total Observations (N) & 8385 & & 2492 & 2.935 \\
\hline
\end{tabular}

Source: Pakistan Integrated Household Survey 1996-97 
Table 2: Descriptive Statistics for Sample of Children Under Five Year

\begin{tabular}{lrrrr}
\hline & \multicolumn{2}{c}{$\begin{array}{c}\text { Middle } \\
\text { Expenditure } \\
\text { Households }\end{array}$} & \multicolumn{2}{c}{$\begin{array}{c}\text { High } \\
\text { Expenditure } \\
\text { Households }\end{array}$} \\
\hline \multicolumn{1}{c}{ Variables } & Mean & $\begin{array}{c}\text { Standard } \\
\text { Dev. }\end{array}$ & Mean & $\begin{array}{c}\text { Standard } \\
\text { Dev. }\end{array}$ \\
\hline Any Treatment (0,1) & 0.96 & 0.19 & 0.96 & 0.19 \\
Modern Treatment (0,1) & 0.75 & 0.44 & 0.88 & 0.32 \\
Any Immunisation (0,1) & 0.79 & 0.41 & 0.86 & 0.35 \\
Reported Episodes (\#) & 0.15 & 0.36 & 0.14 & 0.35 \\
Duration of Reported Episodes (\#) & 6.49 & 5.06 & 5.87 & 4.60 \\
Child Age (Month) & 35.14 & 19.09 & 33.68 & 19.21 \\
Child Age Square (Months) & 1599.1 & 1338.69 & 1502.97 & 1330.16 \\
Whether Male (0,1) & 3 & 0.50 & 0.51 & 0.50 \\
Age of Household Head (Year) & 0.50 & 8.77 & 36.51 & 7.98 \\
Schooling Years of Household Head (Year) & 37.80 & 4.91 & 8.56 & 5.83 \\
Schooling Years of Mother (Year) & 4.52 & 3.26 & 4.24 & 5.21 \\
Whether Urban Residence (0,1) & 1.45 & 0.48 & 0.53 & 0.50 \\
Per Capita Recurrent Government Health & 0.36 & & & \\
Expenditure in Province of Residence (Rs.) & & 22.60 & 106.45 & 22.16 \\
Household Per Capita Monthly Expenditure (Rs.) & 105.75 & 124.82 & 1559.03 & 943.45 \\
Household Size (\#) & 673.84 & 3.289 & 7.48 & 4.306 \\
Total Observations (N) & 7.953 & & 961 & \\
& 4932 & & & \\
\hline
\end{tabular}

Source: Pakistan Integrated Household Survey 1996-97

\section{- Demand for Curative Health Care}

Table 3 and Table 4 show logistic model estimates of both the probability of seeking any treatment for an illness episode reported during the reference period and the probability of seeking treatment from a modern (as opposed to a traditional) provider. Since Likelihood Ratio (LR) tests could not reject the hypothesis of coefficients being independent of household expenditure per capita for both equations, the estimated coefficients are not allowed to vary by per capita expenditure. Indeed, government health expenditure per capita in the province of residence has a significant effect on the probability of seeking any treatment but it has a negative sign. This trend shows that increment in government health expenditure will reduce the probability of seeking any treatment. People will divert to modern treatment. However, a number of other variables also do influence treatment probabilities. These include child age square, and urban residence (with positive effects), and child age (negative effect). The household expenditure elasticity of any treatment is estimated to be 0.14 (see Table-8), while the elasticity of treatment from a modern provider is 0.25 . Controlling for other factors, urban residence increases the probability 
of treatment for an illness episode by about 0.76 and the probability of a modern treatment by 0.87 . Surprisingly, boys have a significantly lower (by about 0.19) probability of receiving treatment for an illness than girls. Indeed, a joint test of significance indicates that the three variables are jointly significant at the 5 percent level.

The reduced-form estimates of the curative care equations differ substantially from the estimates of the full model. In particular, per capita government health expenditure in the province of residence is observed to have a strong negative effect on any treatment. It has a positive impact at higher levels on modern treatment probabilities. This means that the provision of the government health facilities are used more for modern health treatment in Pakistan. People are usually referred to government hospitals, government dispensaries and others government facilities. This means that government health spending is associated with the use of curative health services primarily via other control variables. When evaluated at the sample mean level of household expenditure per capita, the elasticity of any treatment with respect to per capita government health expenditure is estimated to be only 0.013 . However, it varies from 0.012 at a household per capita monthly expenditure level of Rs. 500 to 0.013 at a per capita monthly expenditure of Rs. 1000 and above for the any treatment equation. The elasiticity of modren treatment equation is higher $(0.44$ at sample mean) than that of any treatment equation. It varies from 0.453 to 0.433 for the same monthly expenditure for modern treatment. The high elasticity has low income group, which shows that poor people usually use more government health facilities as compared to rich people. According to this analysis, rich people preferred private health facilities for modern treatment, which also verify the findings of the previous studies related to developing countries.

\section{- Demand for Preventive Health Care}

Table- 5 shows logistic estimates of the probability of a child being immunised against BCG, DPT, measles, or polio. In this case, a LR test significantly rejected the hypothesis of coefficients being independent of $10 \mathrm{~g}$ household expenditure per capita. The association between per capita government health expenditure and the probability of child immunisation is observed to depend significantly on per capita household monthly expenditure. The estimated elasticity of child immunisation with respect to per capita recurrent government health expenditure in province of residence is negative $(-0.45)$ (see Table-8) at the sample mean but varies negligibly with household expenditure per capita. The variables 'whether male', 'whether ubran residence' and 'per capita household monthly expenditure' 
have signficant and positive signs. The above mentioned variables elucidate that immunisation coverage is not only a gender issue in Pakistan, but is also a regional and poverty issue. So the government should allocate more funds for the provision of immunisation of most vulnerable population groups, particularly for rural poor masses. Indeed, the estimated elasticity is slightly negative (although not significantly different from zero) for households having per capita monthly expenditures under Rs. 1000 but it is as large as -0.47 for households spending Rs. 500 per capita per month. The association between use of preventive health services (child immunisation) and per capita recurrent government health expenditure is generally stronger than that between use of curative services and government health spending, presumably because preventive health services, unlike curative services, are typically provided free of charge in Pakistan. However, the finding that there is a positive association between child immunisation rates and government health expenditure is stronger for affluent than for poor households suggests that public preventive health programmes in Pakistan are poorly targeted towards the poor.

The ultimate reduced-form estimates, also shown in Table-5, are similar in sign, although not in magnitude, to the estimate discussed above. The elasticity of child immunisation with respect to per capita government health expenditure is estimated to be -0.069 in the reduced-form model (as opposed to -0.446 in the full mode1). This elasticity ranges from -0.066 for children whose families earn Rs. 500 per capita per month to -0.072 for those whose families earn Rs. 1000 and above per capita per month.

\section{- Child Health Outcomes}

As noted earlier, an important advantage of the reduced-form estimation strategy adopted here is that it is possible to estimate directly the marginal benefits of government spending in terms of health outcomes of different economic groups. Two variables in the Pakistan Integrated Household Survey 1996-97 can be used as proxies for child health outcomes: the probability of an illness episode during the month preceding the survey and the duration of an illness. Unfortunately, the morbidity measures are self-reported. The analysis of self-reported morbidity measures confounds the effects of exogenous variables on true morbidity with those on reporting of morbidity. However, it is often the case that reporting bias is systematically related to variables such as parental education and household expenditure. Although there is control for these variables in the health outcome equations, the bias in the estimated effect of government health expenditure on reported health status is unlikely to be completely eliminated, since individuals living in areas well served by health facilities and well endowed 
with health infrastructure may recognise ill health more accurately, and respond to it with more prompt treatment, than individuals residing in poorly served areas.

The reported duration of an illness and conditions of illness already being reported are likely to be less contaminated by respondent bias. The perception of an illness is likely to vary among persons of different educational status, expenditure backgrounds and among persons residing in urban and rural areas who used different health services provided by the government. Our aim is to explore how best to respond to the public health outcomes through improved access and acceptability of services. This exercise reveals a great deal of inter-country variability and many failures particularly in the provision of health services in the rural areas. Therefore, the reported length of an illness is a useful additional measure for analysing health status. For the purpose of analysis, we use an illness episode in the relevant reference period which is estimated as a dichotomous variable. We assume if a child is ill then we denoted a value of one (1) and if the child is not ill then denoted zero $(0)$. We estimate the relations for the probability of an illness episode during the month preceding the survey by the maximum likelihood logistic method. The illness days are reported of those children who suffered from diarrhea at age 5 years and under and the number of days the child has had diarrhea during the last 30 days. If the child had more than one episode of diarrhea during the last 30 days, sum up the total number of days of all episodes. In the second model illness duration being reported is estimated by Ordinary Least Squares (Table-6).

A $\log$ likelihood Ratio test could not reject the hypothesis that the coefficients of the illness equation were independent of $\log$ household expenditure per capita. The estimates indicate that government health expenditure has a significant positive association with reported morbidity (with an elasticity of morbidity with respect to 'per capita recurrent government health expenditure in province of residence' of 0.39). However, per capita household expenditure has a negative and significant coefficient, which shows a negative association with reported morbidity, most likely reflecting the fact that the reported morbidity is more in poor than in rich households. Counterintuitive results in the illness episode equation include the nonsignificance of urban residence variable, which shows that there is no difference between urban and rural areas for reported illness episode. Other surprising variable is 'mother's schooling' which shows a significant and positive coefficient. This variable is negatively significant in the equation 'duration of illness' which shows that proper care of the educated mother of her child reduces the duration of the morbidity. The non-significance of the 'schooling years of household head' variable is most likely due to the fact that 
educated household heads have a greater propensity to report minor illnesses of their children. But since these households with educated household heads are likely to experience lower levels of actual morbidity among their children, the net effect of schooling of head of household on reported illness incidence is not significantly different from zero.

An F-test also failed to reject the hypothesis that the coefficients of the duration of illness equation are independent of household per capita expenditure (Table-7). Government health expenditure per capita has a strong negative association with illness duration, such that a 6 percent increase in government health spending is associated with a reduction in illness duration of a day. Children in households with better educated mothers tend to have illness episodes of shorter duration, as do boys (relative to girls). Log household per capita monthly expenditure also has a negative sign but it has insignificant coefficient.

\section{Table 3: Probability of Seeking Any Treatment for Illness for Children under Five Year in Pakistan (Using Logit Model)}

\begin{tabular}{|c|c|c|c|c|}
\hline \multirow[t]{2}{*}{ Independent Variables } & \multicolumn{2}{|c|}{ Full Model } & \multicolumn{2}{|c|}{$\begin{array}{c}\text { Reduced Form } \\
\text { Model }\end{array}$} \\
\hline & Paramete & t-ratio & Parameters & t-ratio \\
\hline Intercept & 6.226 & 1.52 & 7.204 & 2.40 \\
\hline Child Age & -0.084 & $-2.31^{* *}$ & & \\
\hline Child Age Square & 0.001 & $2.36^{* *}$ & & \\
\hline Whether Male & 0.190 & 0.69 & & \\
\hline Age of Head of Household & -0.023 & -1.51 & & \\
\hline Schooling Years of Head of Household & 0.013 & 0.34 & & \\
\hline Schooling Years of Mother & -0.029 & -0.54 & & \\
\hline Whether Urban Residence & 0.762 & $2.29 * *$ & & \\
\hline Log household Per Capita Monthly & 0.488 & 1.23 & & \\
\hline Household Size & -0.018 & -0.42 & & \\
\hline $\begin{array}{l}\text { Per Capita Government Health Expenditure in } \\
\text { Province of Residence }\end{array}$ & -1.243 & $1.82^{* * *}$ & -0.888 & -1.38 \\
\hline Log likelihood ratio & & -219.77 & & -228.78 \\
\hline Number of observations & & 1274.00 & & 1274.00 \\
\hline LR statistic $(10 \mathrm{df})$ & & 19.92 & & 1.90 \\
\hline Probability (LR stat) & & 0.03 & & \\
\hline Mean of dependent variable & & 0.96 & & 0.96 \\
\hline
\end{tabular}

* significant at $1 \%$

** significant at $5 \%$

****significant $10 \%$ 
Table 4: Probability of Seeking Modern Treatment for Illness for Children under Five Year in Pakistan (Using Logit Model)

\begin{tabular}{|c|c|c|c|c|}
\hline \multirow[t]{2}{*}{ Independent Variables } & \multicolumn{2}{|c|}{ Full Model } & \multicolumn{2}{|c|}{$\begin{array}{c}\text { Reduced Form } \\
\text { Model }\end{array}$} \\
\hline & Parameters & t-ratio & Parameters & t-ratio \\
\hline Intercept & -8.085 & -4.07 & -2.928 & -2.04 \\
\hline Child Age & -0.038 & $-2.48^{*}$ & & \\
\hline Child Age Square & 0.001 & $2.59^{*}$ & & \\
\hline Whether Male & 0.088 & 0.66 & & \\
\hline Age of Head of Household & -0.011 & -1.48 & & \\
\hline Schooling Years of Head of Household & 0.019 & 1.08 & & \\
\hline Schooling Years of Mother & 0.029 & 1.12 & & \\
\hline Whether Urban Residence & 0.875 & $5.63 *$ & & \\
\hline \multicolumn{5}{|l|}{ Log of Household Per Capita Monthly } \\
\hline Expenditure & 0.902 & $4.69^{*}$ & & \\
\hline Household Size & 0.044 & $1.92^{* *}$ & & \\
\hline \multicolumn{5}{|l|}{ Per Capita Recurrent Government Health } \\
\hline Expenditure in Province of Residence & 0.251 & 0.75 & 0.856 & 0.31 \\
\hline Log likelihood ratio & & -684.48 & & -731.15 \\
\hline Number of observations & & 1274.00 & & 1274.00 \\
\hline LR statistic (10 df) & & 101.05 & & 7.72 \\
\hline Probability (LR stat) & & 0.000 & & \\
\hline Mean of dependent variable & & 0.74 & & 0.74 \\
\hline
\end{tabular}

* significant at $1 \%$

** significant at $5 \%$

$* * *$ significant at $10 \%$ 
Table 5: Probability of Having Received Any Immunisation (Children under Five Years in Pakistan) (Using Logit Model)

\begin{tabular}{|c|c|c|c|c|}
\hline \multirow[t]{2}{*}{ Independent Variables } & \multicolumn{2}{|c|}{ Full Model } & \multicolumn{2}{|c|}{$\begin{array}{c}\text { Reduced Form } \\
\text { Model }\end{array}$} \\
\hline & Parameters & t-ratio & Parameters & t-ratio \\
\hline Intercept & 3.330 & 3.92 & 5.345 & 8.90 \\
\hline Child Age & 0.083 & $14.33^{*}$ & & \\
\hline Child Age Square & -0.001 & $-10.84^{*}$ & & \\
\hline Whether Male & 0.097 & $1.72 * * *$ & & \\
\hline Age of Head of Household & -0.011 & $-3.18^{*}$ & & \\
\hline Schooling Years of Head of Household & 0.055 & $7.23^{*}$ & & \\
\hline Schooling Years of Mother & 0.040 & $3.09 *$ & & \\
\hline Whether Urban Residence & 0.736 & $10.75^{*}$ & & \\
\hline \multicolumn{5}{|l|}{ Log of Household Per Capita Monthly } \\
\hline Expenditure & 0.177 & $2.22 * *$ & & \\
\hline Household Size & 0.012 & 1.31 & & \\
\hline \multicolumn{5}{|l|}{ Log Per Capita Recurrent Government } \\
\hline Health Expenditure in Province of Residence & -1.113 & $-7.76^{*}$ & -0.866 & $-6.69 *$ \\
\hline Log Likelihood Ratio & & -3886.08 & & .4245 .57 \\
\hline Number of Observations & & 8365.00 & & 8365.00 \\
\hline LR Statistic (10 df) & & 763.27 & & 44.29 \\
\hline Probability (LR stat) & & 0.000 & & \\
\hline Mean of Dependent Variable & & 0.79 & & 0.79 \\
\hline
\end{tabular}

* significant at $1 \%$

** significant at $5 \%$

****significant at $10 \%$ 
Table 6: Probability of Reported Illness Episode:

Children Under Five Years, in Pakistan

(Using Logit Model)

\begin{tabular}{|c|c|c|c|c|}
\hline \multirow[t]{2}{*}{ Independent Variables } & \multicolumn{2}{|c|}{ Full Model } & \multicolumn{2}{|c|}{$\begin{array}{c}\text { Reduced Form } \\
\text { Model }\end{array}$} \\
\hline & Parameters & t-ratio & Parameters & t-ratio \\
\hline Intercept & -2.6984 & -2.93 & -3.6689 & -5.40 \\
\hline Child Age & 0.0117 & $1.80 * * *$ & & \\
\hline Child Age Square & -0.0005 & $-5.11 *$ & & \\
\hline Whether Male & 0.1268 & $2.05^{* *}$ & & \\
\hline Age of Head of Household & 0.0083 & $2.26 * *$ & & \\
\hline Schooling Years of Head of Household & 0.0038 & 0.50 & & \\
\hline Schooling Years of Mother & 0.0425 & $3.99 *$ & & \\
\hline Whether Urban Residence & -0.0663 & -0.97 & & \\
\hline Log of Household Per Capita Monthly & & & & \\
\hline Expenditure & -0.1887 & $-2.26^{* *}$ & & \\
\hline Household Size & -0.0131 & -1.29 & & \\
\hline Log Per Capita Recurrent Government Health & & & & \\
\hline Expenditure in Province of Residence & 0.5742 & $3.68 *$ & 0.4220 & $2.88^{*}$ \\
\hline Log Likelihood Ratio & & -3459.54 & & 568.38 \\
\hline Number of Observations & & 8385.00 & & 3385.00 \\
\hline LR Statistics $(10 \mathrm{df})$ & & 225.88 & & 8.21 \\
\hline Probability (LR stat) & & 0.0000 & & \\
\hline Mean of Dependent Variable & & 0.15 & & 0.15 \\
\hline
\end{tabular}

* significant at $1 \%$

** significant at $5 \%$

****significant at $10 \%$ 
Table 7: Duration of Illness: Children Under Five Years in Pakistan (Using Ordinary Least Square Model)

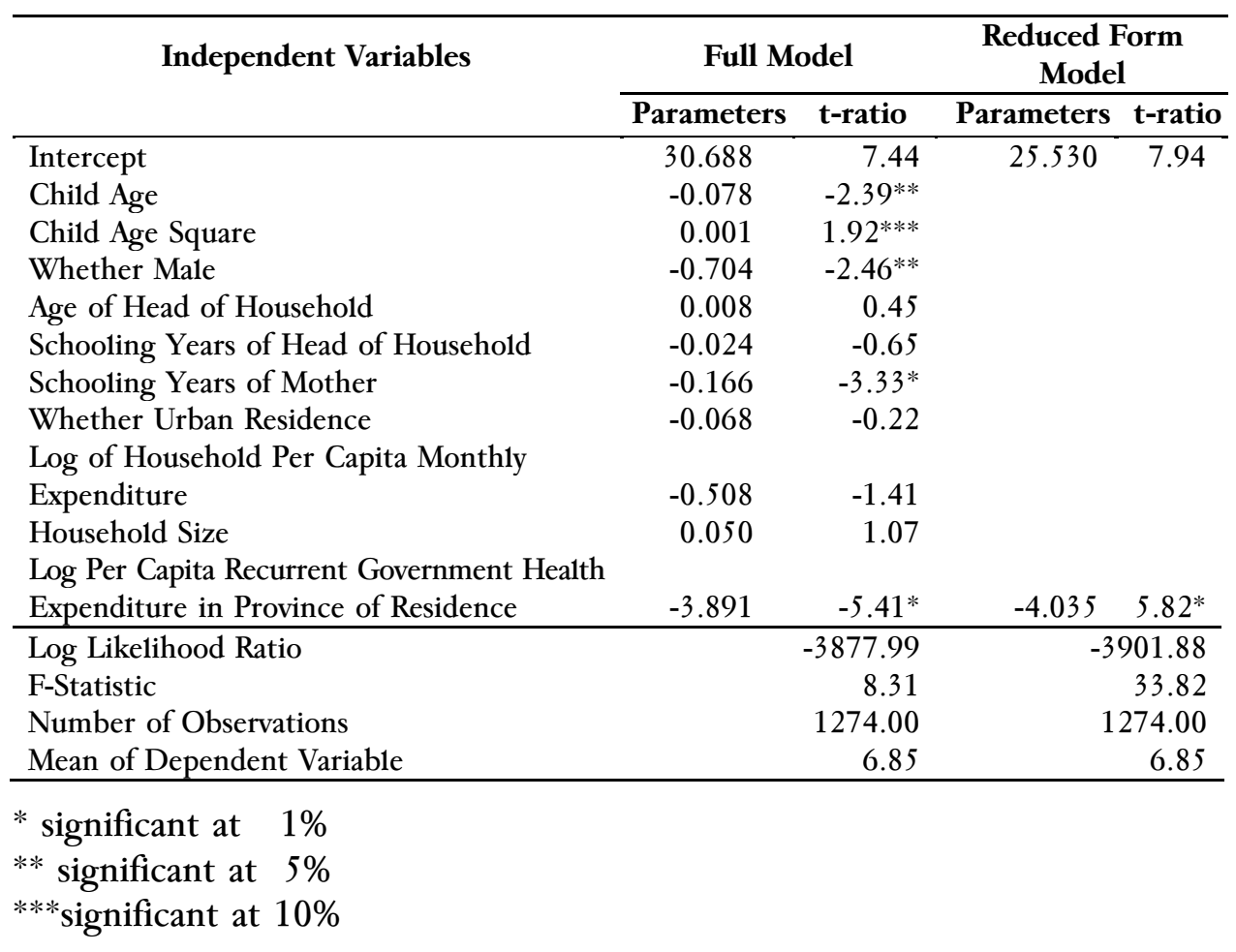


Table 8: Elasticity of Health Care Use and Outcome Variables With

Respect to Government Recurrent Health Expenditure Per Capita (Children Under Five Years in Pakistan: 1996-97)

\begin{tabular}{|c|c|c|c|c|}
\hline Dependent Variable and Model & $\begin{array}{c}\text { At } \\
\text { Sample } \\
\text { Mean }\end{array}$ & $\begin{array}{l}\text { Low } \\
\text { Income } \\
\text { Group }\end{array}$ & $\begin{array}{l}\text { Middle } \\
\text { Income } \\
\text { Group }\end{array}$ & $\begin{array}{l}\text { High } \\
\text { Income } \\
\text { Group }\end{array}$ \\
\hline $\begin{array}{l}\text { - Probability of Any Treatment for Illness } \\
\text { Full Mode1 } \\
\text { Reduced form }\end{array}$ & $\begin{array}{l}-0.141 \\
-0.013\end{array}$ & $\begin{array}{l}-0.130 \\
-0.012\end{array}$ & $\begin{array}{l}-0.145 \\
-0.013\end{array}$ & $\begin{array}{l}-0.147 \\
-0.013\end{array}$ \\
\hline $\begin{array}{l}\text { - Probability of Modern Treatment for } \\
\text { Illness } \\
\text { Full Mode1 } \\
\text { Reduced form }\end{array}$ & $\begin{array}{l}0.251 \\
0.440\end{array}$ & $\begin{array}{l}0.251 \\
0.453\end{array}$ & $\begin{array}{l}0.251 \\
0.436\end{array}$ & $\begin{array}{l}0.251 \\
0.433\end{array}$ \\
\hline $\begin{array}{l}\text { - Probability of Illness Episode } \\
\text { Full Model } \\
\text { Reduced form }\end{array}$ & $\begin{array}{l}0.393 \\
0.382\end{array}$ & $\begin{array}{l}0.398 \\
0.383\end{array}$ & $\begin{array}{l}0.391 \\
0.382\end{array}$ & $\begin{array}{l}0.390 \\
0.381\end{array}$ \\
\hline $\begin{array}{l}\text { - Probability of Any Immunisation } \\
\text { Full Model } \\
\text { Reduced form }\end{array}$ & $\begin{array}{l}-0.446 \\
-0.069\end{array}$ & $\begin{array}{l}-0.467 \\
-0.066\end{array}$ & $\begin{array}{l}-0.438 \\
-0.071\end{array}$ & $\begin{array}{l}-0.434 \\
-0.072\end{array}$ \\
\hline $\begin{array}{l}\text { - Probability of Any Illness } \\
\text { Full Mode1 } \\
\text { Reduced form }\end{array}$ & $\begin{array}{l}-0.568 \\
-0.589\end{array}$ & $\begin{array}{l}-0.568 \\
-0.589\end{array}$ & $\begin{array}{l}-0.568 \\
-0.589\end{array}$ & $\begin{array}{l}-0.568 \\
-0.589\end{array}$ \\
\hline
\end{tabular}

Sources: Table No. 3 to 7

\section{Conclusion and Policy Implications}

There are two major findings of this study. First, the evidence clearly suggests that at the margin, government health expenditures are associated with higher use of both preventive and curative health services by children (the estimates of the reduced-form as opposed to the full models are the ones used in the policy discussion here). However, only households with per capita monthly expenditures of Rs.500 and above appear to realise the beneficial marginal effect of government health expenditure on the health services use of their children (Table-5). Although these households constitute a majority of the sample, the findings imply that the poor in Pakistan do not benefit from government health expenditures. Indeed, the evidence indicates that increased government expenditure is actually associated with lower use of health services by the children of the poor, although this negative association is generally weak. 
Second, the findings with respect to the marginal effect of government health spending on health outcomes are less clear. Government health spending is associated with a reduction in both the incidence and duration of reported morbidity. Since households residing in communities where government health spending is greater and public health infrastructure is better are more likely to report their children's morbidity, the association between government expenditure and true (as opposed to self-reported) child morbidity is likely to be even more negative. In addition, unlike the case with use of health services, the evidence points to government expenditure benefiting (in terms of lowering child morbidity) the poor more than the nonpoor. However, the difference between the marginal effects of spending on the poor and the nonpoor is relatively small.

Thus, with the sole exception of reported morbidity, all the evidence points to the children of high-expenditure households benefiting more (in terms of the marginal effects on both health use and health outcomes) from government health spending than the children of low-expenditure households. Even in the case of reported morbidity, the greater benefit derived by the poor relative to the nonpoor from government health spending is quite small. What could account for the poor benefiting less from government health expenditure than the nonpoor? The earlier discussion of analytical issues suggests that the marginal effect of government spending on the health outcomes of the poor depends on four factors: (a) the extent to which government spending improves access to publicly provided health services for the poor ( $M M / M G$ in relation 3), (b) the effect of increased spending on access to private health services for the poor, (c) the marginal product of government health services for the poor $(M H / M G)$ and (d) the marginal product of private health services for the poor. Since the poor consume less of both public and private medical care than the nonpoor, a priori one would expect that the public and private health inputs have larger marginal effects on their health outcomes. However, if increased government spending improves health care opportunities for the nonpoor more than for the poor, the total effect of government spending on the health outcomes of the poor could be smaller even though they have a higher marginal product of health care inputs.

The progress in the expansion of health facilities and health manpower remained sluggish for many years because of the low priority given to the health sector, which led to an extremely inadequate distribution of health facilities in both urban and rural areas. More than four-fifths of the health budget in Pakistan gets allocated to urban-based curative health facilities at the expense of rural health programmes. An important reason for a lack of trained medical manpower in rural areas is 
lack of facilities. Even if some well- intentioned doctors want to serve in rural areas, the abysmal conditions force them to change their mind (Zaidi 2000). In urban areas, these health facilities are largely restricted to use by the upper sections of society and are beyond the reach of those living in slums and katchi abadis. Pakistan has undergone a very fast rate of urbanisation at around 4.8 per cent per annum (Pakistan Census Report 1998), largely due to migration from rural areas. Thus, slums and katchi abadis constitute a large section - around 40 per cent nationwide - of the urban populace. Health centres and other medical facilities are virtually nonexistent in these settlements.

Economic growth accompanied by macroeconomic stability remains critical for Pakistan to reduce poverty. At the household level, growth serves to reduce poverty and better enables households to secure proper nutrition and health care. At the macro level, growth generates greater resources which can finance improved coverage and quality of health and other services. Growth itself will depend on many factors including the investment climate and increased opportunities for trade access to developed markets but also, a healthy, better educated and more productive labour force. To increase access to basic health services particularly emphasis on females for rural and semi-urban populations, there is an excellent example in the Rural Social Development Programme which was envisaged as one of the European Union's Poverty Reduction initiatives in Pakistan. The findings of our study also justify this approach particularly for Pakistan and other developing countries. 


\section{References}

Akin, John S., Nancy J. Birdsall, and D. de Ferranti, 1987, "Financing Health Services in Developing Countries: An Agenda for Reform.” A World Bank Policy Study. Policy and Research Division of The Population, Health and Nutrition Development. Washington, D.C. World Bank.

Behrman, J. R., and A.B. Deolalikar, 1987, "Will Developing Country Nutrition Improve with Income? A Case Study for Rural South India." Journal of Political Economy, 95(3), pp 492-507.

Behrman, J. R., and B. L,, Wolfe, 1987, "How Does Mother's Schooling Affect the Family's Health, Nutrition, Medical Care Usage, and Household Sanitation.”, Journal of Econometrics; 36(1-2), pp 185-204.

Deolalikar, Anil B., 1995, "Government Health Spending in Indonesia: Impacts on Children in Different Economic Groups",In H. Chenery and T. N. Srinivasan (eds) Handbook of Development Economics. 1. Chapter 14, Elsevier Science Publishers.

Folbre, N., 1986, "Cleaning House: New Perspectives on Households and Economic Development”, Journal of Development Economics, 22(1), pp 5-40.

Folbre, N., 1984a, "Market opportunities, genetic endowments, and intrafamily resource allocation": Comments, American Economic Review 74(3), pp 518-20.

Folbre, N., 1984b, "Household Production in the Philippines: A NonNeoclassical Approach", Economic Development and Cultural Change 32(2), pp 303-30.

Gertler, Paul, and Jacques van der Gaag, 1990, The Willingness to Pay for Medical Care: Evidence from Two Developing Countries. Baltimore, Md.: Johns Hopkins University Press.

Gilleskie, Donna ,B., 1998, A Dynamic Stochastic Model of Medical Care Use and Work Absence”, Econometrica 66(1), pp 1-45.

GOP, 1998, Pakistan Integrated Household Survey 1996-97 Statistics Division, Government of Pakistan, Islamabad. 
Guilkey David K, and Riphahn Regina T., 1998, "The Determinants of Child Mortality in the Philippines: Estimation of a Structural Model ", Journal of Development Economics 56(2), pp 281-305.

Lee Lung Fei and Rosenzweig Mark R., 1997, The Effects of Improved Nutrition, Sanitation, and Water Quality on Child Health in HighMortality Populations”, Journal of Econometrics 77(1), pp 209-35.

Manser, M. and M. Brown, 1980, "Marriage and Household DecisionMaking: A Bargaining Analysis." International Economic Review 21(1), pp 31-44.

McElroy, M.B. and M. J. Horney, 1981, "Nash-Bargained Household Decisions: Toward a Generalization of the Theory of Demand.", International Economic Review 22(2), pp333-50.

Meerman, Jacob, 1979, Public Expenditure in Malaysia: Who Benefits and Why. New York: Oxford University Press.

GOP (1998), Pakistan Census Report, Census Commission, Government of Pakistan.

Rosenzweig, M.R. and T.P. Schultz, 1982a, "Child Mortality and Fertility in Columbia: Individual and Community Effects”, Health Policy and Education 2, pp 305-348.

Rosenzweig, M. R., and T. P., Schultz, 1982b, "Market Opportunities, Genetic Endowments and Intrafamily Resource Distribution: Child Survival in Rural India”, American Economic Review, 72(4), pp 803-15.

Selowsky, Marcelo, 1979, "Who Benefits from Government Expenditures? A Case Study of Colombia." New York: Oxford University Press.

Shuemli, Amir, 2001, "The Effect of Health on Acute Care Supplemental Insurance Ownership: An Empirical Analysis." Health Economics 10(4), pp 341-50.

Zaidi Akbar S., 2000, Issues in Pakistan Economy, Oxford Printing Press, Karachi Pakistan. 